цьтрафиолетовая терапия Аальнего Алинноволнового диапазона (УФА-1-терапия) в мечении больных атопическим Аерматитом

(С Кубанов А.А., Чикин В.В. ${ }^{*}$ Карамова А.Э., Давлетбаева Л.Х.

Государственный научный центр дерматовенерологии и косметологии

107076, Россия, г. Москва, ул. Короленко, д. 3, стр. 6

Одним из методов терапии атопического дерматита является общая ультрафриолетовая терапия дальнего длинноволнового диапазона (УФА-1-терапия). В обзоре литературы рассматриваются механизмы терапевтического действия УФА-1-терапии. Приведен анализ эфрфективности УФА-1-терапии больных атопическим дерматитом с учетом факторов, которые могут влиять на эффрективность лечения, - дозы излучения, фототип кожи пациентов, проведение сопутствующей лекарственной терапии. Представлены имеющиеся данные об уменьшении степени тяжести атопического дерматита в результате курса УФА-1-терапии и об уменьшении у пациентов выраженности зуда. Рассмотрены данные о скорости наступления терапевтического эффекта УФА-1-терапии и продолжительности его сохранения. Обсуждается безопасность УФА-1-терапии, приводятся наиболее частые нежелательные эффректы - ощущение тепла, жара, зуд, гиперпигментация. Оценивается возможность развития нежелательных явлений, требующих прекращения лечения. Полученные данные свидетельствуют об эффрективности и безопасности использования УФА-1-терапии для лечения больных атопическим дерматитом средней и тяжелой степени тяжести.

Ключевые слова: атопический дерматит, общая ультрафиолетовая терапия дальнего длинноволнового диапазона, УФА-1-терапия, эффективность, безопасность.

Конфрликт интересов: авторы данной статьи подтвердили отсутствие конфликта интересов, о котором необходимо сообщить.

Источник фринансирования: работа выполнена за счет финансирования по месту работы авторов.

Для цитирования: Кубанов А.А., Чикин В.В., Карамова А.Э., Давлетбаева Л.Х. Ультрасиолетовая терапия дальнего длинноволнового диапазона (УФА-1-терапия) в лечении больных атопическим дерматитом. Вестник дерматологии и венерологии. 2021;97(5):26-37. doi: https://doi.org/10.25208/vdv1286 


\title{
Jong-wavelength ultraviolet A (UVA-1) phototherapy for the treatment of patients with atopic dermatitis
}

\author{
(C) Alexey A. Kubanov, Vadim V. Chikin*, Arfenya E. Karamova, Liaisan K. Davletbaeva
}

State Research Center of Dermatovenereology and Cosmetology

Korolenko str., 3, bldg 6, 107076, Moscow, Russia

One of the methods of therapy for atopic dermatitis is long-wavelength ultraviolet therapy A (UVA-1therapy). This review aims to provide the mechanisms of action of UVA-1-therapy an overview about the effectiveness of UVA-1-therapy in patients with atopic dermatitis taking into account factors that can affect the effectiveness of treatment - radiation dose, skin phototype of patients, concomitant drug therapy. The available data on a decrease in the severity of atopic dermatitis as a result of the course of UVA-1-therapy and on a decrease in the severity of itching in patients are presented. The data on the rate of onset of the therapeutic effect of UVA-1-therapy and the duration of its maintenance are considered. The safety of UVA-1-therapy is discussed, and the most frequent undesirable effects - a feeling of warmth, fever, itching, hyperpigmentation, are given. The possibility of developing side effects requiring discontinuation of treatment is assessed. The data obtained indicate the effectiveness and safety of the UFA-1-radiation in the treatment of patients with moderate-to-severe atopic dermatitis.

Keywords: atopic dermatitis, phototherapy, UVA-1-therapy, efficacy, safety.

Conflict of interest: the authors declare that there are no obvious and potential conflicts of interest associated with the publication of this article.

Source of funding: the work was done through financing at the place of work of the authors.

For citation: Kubanov AA, Chikin VV, Karamova AE, Davletbaeva LK. Long-wavelength ultraviolet A (UVA-1) phototherapy for the treatment of patients with atopic dermatitis. Vestnik Dermatologii i Venerologii. 2021;97(5):26-37. doi: https://doi.org/10.25208/vdv1286 


\section{Введение}

Атопический дерматит - мультифакторное генетически детерминированное воспалительное заболевание кожи, имеющее хроническое рецидивирующее течение и характеризующееся зудом, возрастными особенностями локализации и морфологии очагов поражения. Его развитие связано с нарушением функционирования защитного кожного барьера эпидермиса и формированием в коже воспалительной реакции, реализуемой главным образом CD4+ Т-лимфоцитами [1-4]. При обострениях атопического дерматита очаги поражения кожи инфильтрированы преимущественно CD4+ Th2-лимфоцитами, которые секретируют провоспалительный цитокин интерлейкин (ИЛ-4, ИЛ-5 и ИЛ-13, ИЛ-31) [5-8]. Кроме того, в составе воспалительного инфильтрата помимо Th2-лимфоцитов присутствуют также Th17- и Th22-лимороциты, продуцирующие ИЛ-17 и ИЛ-22 соответственно [9-12]. В длительно существующих очагах поражения атопического дерматита вместе c Th2-, Th17- и Th22-лимороцитами в инфильтрате появляется значительное количество Th1-лимфоцитов, продуцирующих интерферон (ИФН- $\gamma)$ и фрактор некроза опухоли (ФНО- $\alpha)$ [1, 11-13].

Нарушение функционирования защитного барьера эпидермиса у больных атопическим дерматитом вызвано нарушением синтеза липидов и структурных белков эпидермиса - филаггрина, лорикрина, инволюкрина - и может быть обусловлено генетически или возникнуть вследствие развивающейся воспалительной реакции. Известно, что с нарушением барьерной функции кожи и развитием этого заболевания ассоциированы мутации гена фрилаггрина [14]. В то же время возникновению дефекта эпидермального барьера и ухудшению его функционирования способствуют цитокины, продуцируемые клетками воспалительного дермального инфильтрата и способные подавлять активность генов, ответственных за процессы терминальной дифференцировки кератиноцитов [15-20]. Показано, что в кератиноцитах, диффреренцировка которых происходила в присутствии ИЛ-4 и ИЛ-13, значительно уменьшалась экспрессия гена фрилаггрина, даже в случае отсутствия его мутаций [18]. ИЛ-4 и ИЛ-13 уменьшают также экспрессию кератиноцитами лорикрина и инволюкрина [16]. Получены данные о том, что экспрессию филаггрина способны подавлять ИЛ-17 и ИЛ-22, что также ведет к нарушению функционирования защитного кожного барьера $[17,21]$.

ИЛ-10, продуцируемый Th2-лимфоцитами, моноцитами, макрофагами, дендритными клетками, тучными клетками, В-лимфоцитами и кератиноцитами, направляет развивающуюся воспалительную реакцию по Th2-пути [22, 23]. С другой стороны, ИЛ-10 оказывает противовоспалительное действие, ограничивая распространение аллергической воспалительной реакции [22-25]. Поэтому с дефицитом ИЛ-10 связывают тяжелое течение атопического дерматита и развитие выраженных обострений болезни [25-29].

Значение Т-лимфоцитов и цитокинов, ими продуцируемых, в развитии воспаления у больных атопическим дерматитом обосновывает необходимость патогенетической терапии, направленной на подавление воспалительной Т-клеточной реакции в дерме. С этой целью может применяться фоототерапия, в основе которой лежит ультрафиолетовое (УФ) облучение кожи.
УФ-излучение характеризуется длинами волн от 100 до 400 нм, занимая спектральный диапазон между видимым светом и рентгеновским излучением. В зависимости от оказываемых биологических эффректов ультрафиолетовое излучение разделяют на 3 диапазона. По порядку длин волн от самых коротких до самых длинных выделяют коротковолновое, УФС (200-290 нм), средневолновое, УФВ (290-320 нм) и длинноволновое УФА-излучение (320-400 нм), которое дополнительно разделяют на УФА-2 (320-340 нМ) и УФА-1-излучение (340-400 нм) [30, 31].

Для терапии заболеваний кожи используется ультрафиолетовое излучение диапазонов А и В. Наименее энергетическим из всех фракций УФ-излучения является УФА-1-диапазон (340-400 нм), который спектрально наиболее близок к видимому свету. Поскольку УФА-1-излучение обладает самой низкой энергией излучения в ультрафиолетовом спектре, предполагается, что оно в наименьшей степени оказывает повреждающее действие, в том числе в отношении ДНК [32]. В начале 80-х гг. XX в. с целью минимизировать нежелательные явления фрототерапии, обусловленные содержанием в УФА-излучающих лампах эритемогенного УФБ-излучения, способного вызывать эритему и ожоги кожи, были разработаны аппараты для проведения УФА-1-терапии [32, 33]. Эти аппараты должны соответствовать ряду технических требований. Эритемогенное излучение для длины волны $\lambda<340$ нм не должно превышать 5\% от общего излучения, испускаемого его источником. Совсем незначительным должно быть содержание излучения с длинами волн $\lambda<320$ нм. Должна быть предусмотрена возможность эфрфрективной фрильтрации инфракрасного света; излучение с длинами волн $\lambda>800$ нм $<1$ мм должно составлять менее 5\% от общей плотности потока излучения [34].

В настоящее время в качестве источников излучения для УФА-1-фототерапии используются люминесцентные или металлогалогеновые лампы. В этих аппаратах исключена близкая по своим биологическим эффектам к УФБ-излучению (280-320 нм) УФА-2-часть УФА-диапазона (320-340 нм), считающаяся более эритемогенной, чем УФА-1-излучение [33-36]. В связи с этим порог эритемы для источников УФА-1-света очень Высок и во время курса лечения достигается только у незначительного числа пациентов [32]. При оценке минимальной эритемной дозы, индуцируемой УФА-1-излучением, обнаружено, что среди участников исследования, среди которых 51\% был со II фототипом кожи, 40\% - с III фототипом и 9\% - с IV фототипом, у большинства (56\%) минимальная эритемная доза УФА-1-излучения превысила 130 Дж/см², у 30\% участников минимальная эритемная доза составляла от 70 до 130 Дж/см², у 14\% от 20 до 70 Дж/см² [37].

В начале 90-х гг. XX в. УФА-1-терапия была внедрена в практику как метод фототерапии с наименьшим количеством побочных эфффектов фототерапии [31]. При проведении УФА-1-терапии выделяют низкие, средние и высокие дозы УФА-1-излучения, несколько различающиеся в Европе и США. В Европе низкими дозами УФА-1-тера-

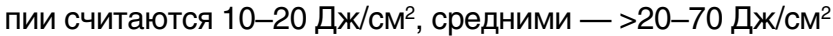
и высокими - >70-130 Дж/см² [34]. В Соединенных Штатах США в качестве низких доз УФА-1-терапии рассма-

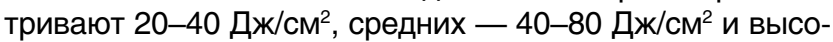
ких - 80-120 Дж/см² [30]. 
Устройства, содержащие люминесцентные и металлогалогеновые лампы, существенно различаются по своей стоимости и мощности. Кабины с люминесцентными лампами дешевле и характеризуются меньшей мощностью, они позволяют проводить терапию низкими и средними дозами УФА-1-излучения. Терапия высокими дозами (до 130 Дж/см²) возможна только при использовании металлогалогеновых ламп.

\section{Механизмы действия УФА-1-терапии}

Эффрективность УФА-1-терапии связана с подавлением воспалительной реакции за счет индукции апоптоза лимсроцитов, тучных клеток и клеток Лангерганса и ингибирования продукции Th2-цитокинов ИЛ-5, ИЛ-13 и ИЛ-31 [30, 31, 38]. Иммуносупрессивные эфрфекты УФА-1-излучения отличаются от эфрфектов других спектров ультрафриолетового излучения [32].

В связи с тем, что при прохождении УФА-излучения через ткани его энергия поглощается гораздо медленнее по сравнению с УФ-излучением диапазонов В и С, оно характеризуется наиболее глубоким проникновением и способно проникать на всю толщу дермы и даже в подкожную клетчатку, где может оказывать свое воздействие. Развитие фотобиологических эфффектов УФА-1-терапии связывают с поглощением энергии УФА-излучения хромофрорами [32]. Основными хромофрорами кожи, поглощающими УФА-1-излучение, считаются порфирины и рибофрлавины [34, 39]. Кроме них в коже присутствуют такие хромофоры, как меланин (в эпидермисе), гемоглобин и билирубин (в кровеносных сосудах дермы) [32].

Хромофроры представляют собой молекулы, которые благодаря своей химической структуре способны поглощать электромагнитную энергию и переносить ее на другие молекулы. Перенос хромофрорами энергии УФА-излучения на молекулы кислорода приводит к образованию активных фрорм кислорода - синглетного кислорода $\left(1 \mathrm{O}_{2}\right)$ и супероксидных анионов $\left(\cdot \mathrm{O}_{2}-\right)$ и в дальнейшем - перекиси водорода и гидроксильных радикалов $(\bullet \mathrm{OH})$ [31]. Апоптоз Т- и В-лимфоцитов и незрелых пролиферирующих тучных клеток после воздействия УФА-1-излучения обусловлен образованием активных фрорм кислорода [40, 41]. Известны 2 механизма активации апоптоза, развивающегося после воздействия УФА-1-излучения. Один из них обусловлен действием супероксидных анионов, а другой является эффектом синглетного кислорода.

Оба механизма УФА-1-вызванного апоптоза включают воздействие активных фрорм кислорода на мегапоры клеточных митохондрий, которые представляют собой комплекс белков, представляющий собой канал, проходящий через наружную и внутреннюю мембраны митохондрии и функционирующий путем изменения конформации составляющих ее белков, регулируя тем самым активность метаболических процессов [42]. В результате повреждения мегапор супероксидными анионами высвобождается цитохром С, что активирует каспазозависимый, нечувствительный к циклоспорину А апоптоз лимфроцитов и незрелых тучных клеток [40]. Иначе действует синглетный кислород, который деполяризует мембраны митохондрий внутри клетки, приводя к открытию чувствительной к циклоспорину А митохондриальной мегапоры. Это приводит к высвобождению фрактора, инициирующего апоптоз (AIF), который, в свою очередь, активирует другой каспазозависимый апоптотический каскад [40].
Особенностью апоптоза, индуцируемого УФА-1-излучением, является то, что он инициируется практически немедленно (менее 20 минут) после воздействия, поскольку в его развитии участвуют внутриклеточные белки, присутствующие в клетке и не требующие предварительного синтеза [40]. Этим УФА-1-терапия отличается от УФВ- и ПУВА-терапии, после воздействия которых для развития апоптоза требуется время на синтез и накопление в клетке проапоптотических белков, например белка р53, индуцирующих запрограммированную гибель клеток $[40,43]$.

Поскольку гидроксильные радикалы, образующиеся после воздействия УФА-излучения, способны повреждать все компоненты ДНК, излучение этого спектра может также вызывать повреждение ДНК, хотя и менее выраженное по сравнению с воздействием УФВ-излучения. В связи с этим апоптоз клеток воспалительного инфильтрата после воздействия УФА-1-излучения связан не только с активацией каспаз вследствие образования активных форм кислорода, но и с прямым повреждением клеточной ДНК [32, 44]. Кроме того, хромофоры после поглощения энергии УФА-излучения могут передавать ее энергию не только молекулам кислорода, но и непосредственно ДНК в фрорме одноэлектронного окисления. Основными продуктами окислительного повреждения клеток, опосредованного УФА-излучением, являются окисленные пуриновые и пиримидиновые основания, например 8-оксогуанин, который даже рассматривается как биоиндикатор воздействия УФА-излучения [31]. Помимо окисления пуриновых и пиримидиновых оснований, воздействие УФА-излучения также приводит к однонитевым разрывам ДНК и транзициям (заменам) $\mathrm{C} \rightarrow \mathrm{T}$, аналогичным тем, что наблюдаются после УФВ-облучения.

Апоптоз клеток воспалительного инфильтрата в коже больных атопическим дерматитом, получающих УФА-1-терапию, сопровождается уменьшением продукции воспалительных цитокинов. УФА-1-излучение подав-ляет продукцию ФНО- $\alpha$ и ИЛ-12 [32, 45]. Воздействие УФА-1-излучения также может привести к уменьшению уровня содержания в коже ИФН- $\gamma$ и ICAM-1, которые участвуют в активации лимфоцитов, и их переходу в ткани соответственно [30, 46, 47]. С другой стороны, УФА-1-излучение стимулирует продукцию кератиноцитами ИЛ-10, обладающего противовоспалительными свойствами. ИЛ-10 подавляет антигенпрезентирующую фрунцию дендритных клеток и продукцию провоспалительных цитокинов Т-лимфоцитами (ИЛ-1, ИЛ-6, ИЛ-8, ИЛ-12, ФНО- $\alpha$ ) [48].

Тем самым УФА-индуцированное окислительное и прямое повреждение клеток, индуцирующее апоптоз клеток воспалительного инфильтрата, особенно Т-лимфоцитов, вызывает противовоспалительный эффект и может приводить к улучшению состояния больных атопическим дерматитом [31].

Эфрфективность УФА-1-терапии может быть различной у разных больных. Она может зависеть как от характеристик излучения, например его дозы, так и от индивидуальных особенностей пациентов, например от фототипа кожи. В связи с этим мы поставили цель оценить по данным литературы клиническую эффективность УФА-1-терапии больных атопическим дерматитом и определить факторы, которые могут влиять на эффрективность лечения. 


\section{Результаты анализа данных об эффективности УФА-1-терапии}

Был проведен анализ литературы, обнаруженной в базах данных научной литературы PubMed и РИНЦ при поиске по ключевым словам атопический дерматит (atopic dermatitis, atopic eczema) и УФА-1-терапия (UVA-1-therapy). Если авторами публикаций не проводилась оценка динамики степени тяжести атопического дерматита, то для оценки эффрективности УФА-1-терапии больных атопическим дерматитом мы рассчитывали в процентах уменьшение степени тяжести заболевания независимо от использовавшегося в исследовании индекса тяжести болезни и уменьшение интенсивности зуда, если такие данные имелись. Учитывали дозы назначавшегося УФА-1-излучения, фототипы кожи больных, которым эта терапия назначалась. Характеризовали режимы проводимой УФА-1-терапии. Для оценки безопасности УФА-1-терапии анализировали характер и частоту возникновения нежелательных явлений.

Поиск в базах данных научной литературы PubMed и РИНЦ обнаружил 21 исследование различного дизайна, в которых оценивалась клиническая эффективность УФА-1-терапии больных атопическим дерматитом. Среди них было 7 несравнительных исследований, в которых оценивалась только динамика состояния пациентов после курса лечения, и 14 сравнительных исследований. Дизайн сравнительных исследований эффрективности УФА-1-терапии включал 2 варианта. Один вариант предусматривал формирование двух или более групп пациентов, которые получали лечение разными дозами УФА-1-излучения или другими методами фототерапии (УФВ-311) [49], ПУВА-терапия [50], УФА-1-фототерапия холодным светом [51, 52], комбинированное УФА/УФВ-излучение [51-54], топические кортикостероиды [54] или такролимус [55]. Проводилось также сравнение эфффективности различных доз УФА-1-терапии: высоких и средних [56, 57], низких и средних [58], высоких, средних и низких [59]. Оценивалась динамика тяжести атопического дерматита в группе больных, получавших УФА-1-терапию в комбинации с лекарственной терапией, в сравнении с группой больных, которым проводилась только лекарственная терапия [60].

Другим вариантом сравнительных исследований были 3 исследования, в которых формировалась только одна группа пациентов. Но в этих сравнительных исследованиях с участием одной группы пациентов УФА-1-излучению в определенной дозе подвергали только одну половину тела пациентов, а другую либо облучали излучением другого спектра (УФБ-311) [61, 62], либо использовали другую дозу УФА-1-излучения [56].

В группы больных, которым проводилась УФА-1-терапия, были включены 503 больных атопическим дерматитом. УФА-1-терапия проводилась пациентам с атопическим дерматитом средней и тяжелой степени тяжести, за исключением одного исследования, в котором была сформирована группа больных с легким атопическим дерматитом [63]. Для оценки степени тяжести болезни использовали различные индексы: SCORAD - в 14 исследованиях, оценку по Costa - в трех, SASSAD - в двух, EASI и лестерскую шкалу признаков LSS - по одному.

Распределение больных по фототипам кожи было подробно описано в 8 исследованиях, в которые были включены 1 пациент с I фототипом кожи, 45 пациентов - со II фоототипом, 99 пациентов - с III фототипом, 14 пациентов - c IV фототипом [51, 53-58, 64]. В одном исследовании указания на фототип кожи были недостаточно определенными, так как распределение по фототипу кожи приводилось для всех включенных в исследование пациентов без учета того, что они затем были рандомизированы в группы, получавшие лечение различными методами [50]. В 12 исследованиях фрототип кожи пациентов не определялся.

Режим УФА-1-терапии, рекомендованный больным атопическим дерматитом, был различным. Первоначально описывались результаты лечения, при котором процедуры назначали ежедневно в течение 10 или 15 дней (в режиме с ежедневным процедур в течение 10 или 15 дней) [53, 54]. В последующем от ежедневного режима УФА-1-излучения отказались. Процедуры УФА-1-терапии могли 3 раза в неделю в течение 6,8 или 4-8 недель [49, 61, 62, 65]. Но чаще всего использовался режим терапии, при котором процедуры УФА-1-облучения назначали 5 раз в неделю в течение 3 недель [50-52, 56, 58, 59, 64]. Использовались также режимы терапии 5 раз в неделю в течение 4 или 5 недель [55, $60,55-68]$. В ряде исследований частота проведения УФА-1-терапии пациентам с атопическим дерматитом варьировала и составляла 3-5 раз в неделю или 4-5 раз в неделю [57, 63, 69, 70].

Указания на проведение сопутствующей терапии были представлены в 19 исследованиях. В 16 исследованиях сопутствующая терапия ограничивалась использованием эмолиентов. В 3 исследованиях дизайном предусматривалось одновременное проведение системной и наружной лекарственной терапии. Помимо эмолиентов пациентам могли назначаться антигистаминные, мембраностабилизирующие и седативные средства, сорбенты, наружно - пасты и кремы, содержащие насталан, АСД 3-й фракции, ихтиол, водные растворы анилиновых красителей $[60,63,70]$. В двух исследованиях не было указаний, проводилась ли пациентам какая-либо сопутствующая лекарственная терапия [57, 69].

Нами был проведен анализ эффективности различных доз УФА-1-излучения в терапии больных

Таблица. Эффективность УФА-1-терапии больных атопическим дерматитом в различных дозах УФА-1-излучения вне зависимости от фототипа кожи в отсутствие сопутствующей терапии Table. The effectiveness of UVA-1-therapy in patients with atopic dermatitis in various doses of UVA-1-radiation, regardless of the skin phototype in the absence of concomitant therapy

\begin{tabular}{cccc}
\hline Дозы & Кумулятивные дозы, Дж/см² & $\begin{array}{c}\text { Уменьшение степени тяжести } \\
\text { атопического дерматита }\end{array}$ & Ссылки \\
\hline Низкие & $276 \pm 43$ & Ha $15,1 \%$ & {$[59]$} \\
\hline Средние & $750-1000$ & Ha 28,7-58,8\% & {$[49-52,56-59,61,62,64-66,68]$} \\
\hline Высокие & $1300-1950$ & Ha 34,7-75,4\% & {$[53,54,56,57,59,69]$} \\
\hline
\end{tabular}


атопическим дерматитом (таблица). Результаты терапии низкими дозами УФА-1-облучения значительно различались в зависимости от использования сопутствующей лекарственной терапии. В двух исследованиях эффективности УФА-1-терапии в низких дозах, проводившейся в режиме 5 раз в неделю в течение 3 недель, запрещалось любое системное и наружное лекарственное лечение, и пациенты могли использовать только эмолиенты [58, 59]. H.C. Dittmar и соавт. (2001) показали, что лечение низкими дозами УФА-1-облучения (кумулятивная доза $276 \pm 43$ Дж/см²) было неэффрективным, приведя к уменьшению значения индекса SCORAD лишь на 15,1\% [59]. По данным Kowalcir и соавт. (1995), УФА-1-терапия в низких дозах (кумулятивная доза 150 Дж/см²) оказалась значительно менее эфффективной, чем лечение средними дозами УФА-1-излучения (кумулятивная доза 750 Дж/см²) [58]. Авторами сделано заключение, что использование низких доз УФА-1-излучения для терапии больных атопическим дерматитом нельзя считать оптимальным [58].

Вместе с тем сочетание УФА-1-терапии низкими дозами с системной терапией антигистаминными и мембраностабилизирующими препаратами, а также с наружной лекарственной терапией, приводило к ее значительной эффективности. Показано, что в таком сочетании курсы УФА-1-терапии, состоявшие из 8-25 процедур и проводившиеся в режиме 4-5 раз в неделю с кумулятивными дозами облучения от 130 до 400 Дж/см² и 382,1 $\pm 133,5$ Дж/см², приводили к уменьшению значения индекса SCORAD на 73,3-78,2\% [60, 63, 70].

В 15 исследованиях оценивалась эффективность средних доз УФА-1-терапии [49-52, 55-59, 61, 62, 64-66, 68]. Кумулятивная доза УФА-1-излучения, полученная больными атопическим дерматитом, составляла от 750 Дж/см² до 1000 Дж/см². В 13 исследованиях эффективность средних доз УФА-1-терапии в лечении больных атопическим дерматитом была расценена как значительная. Степень тяжести атопического дерматита в конце курса УФА-1-терапии средними дозами уменьшалась на 28,7-58,8\%. При этом в анализ не включались результаты УФА-1-терапии средними дозами, представленные графически без указания значения индекса степени тяжести атопического дерматита после проведенного лечения, что не позволяло количественно оценить динамику тяжести болезни [56, 58].

В исследовании, проведенном F. Legat и соавт. (2003), изменения степени тяжести атопического дерматита после курса терапии средними дозами УФА-1-излучения не достигли уровня статистической значимости $(p=0,055)$, однако в него было включено наименьшее количество пациентов - 9 человек, что снижает его статистическую мощность и вероятность обнаружить значимые различия, если они имеются [62].

В 6 исследованиях оценивалась эффрективность высоких доз УФА-1-терапии [53, 54, 56, 57, 59, 69]. В 5 из них представлены данные о значительном уменьшении степени тяжести атопического дерматита. Терапия пациентам проводилась в различных режимах: 10 или 15 процедур ежедневно, 10 процедур в режиме 3-5 раз в неделю, а в трех исследованиях - 15 процедур в режиме 5 процедур в неделю в течение 3 недель. Кумулятивная доза составляла

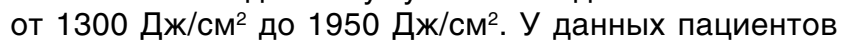
было отмечено уменьшение степени тяжести болезни на 34,7-75,4\%. Прямое сравнение эфффективности терапии высокими и средними дозами УФА-1-излучения не выявило статистически значимых различий [56].

В анализ эффективности УФА-1-терапии высокими дозами не были включены результаты исследования, представленные графически без указания значения индекса степени тяжести атопического дерматита после проведенного лечения [54]. Кроме того, S. Tzaneva и соавт. (2001) не указали, достигли ли уровня статистической значимости изменения степени тяжести заболевания в процессе лечения высокими дозами УФА-1-излучения [56].

При оценке влияния фототипа кожи на результаты УФА-1-терапии показано, что средние дозы УФА-1-излучения в режиме терапии 5 процедур в неделю в течение 3 недель (кумулятивная доза - 750 Дж/см²) были эффрективны в лечении пациентов со светлой кожей (фототипы I и II) [57]. Курс лечения, включавший 15 процедур облучения в режиме 5 раз в неделю в течение 3 недель (кумулятивная доза 750 Дж/см²), приводил к уменьшению значения SCORAD на $34,59 \%$. Однако у пациентов с темной кожей (фототипы III и IV) УФА-1-терапия средними дозами была неэффективной, значение SCORAD после курса лечения уменьшилось у них на 11,02\% [57]. Обнаружено также, что эффрективность УФА-1-терапии в высоких дозах, в отличие от средних доз, не зависит от фототипа кожи, и у больных c III-IV фототипами значение SCORAD в аналогичном режиме уменьшалось на 44,22\%, а у больных с I-II фототипами - на 35,9\% [57].

Влияние УФА-1-терапии на интенсивность зуда оценивалось в 6 исследованиях, в которых УФА-1-излучение назначалось в средних дозах $[49,61,62,65$, $66,68]$. Было показано, что за 24 процедуры УФА-1-облучения (кумулятивная доза - 930,6 Дж/см²) в режиме 3 раза в неделю в течение 8 недель интенсивность зуда уменьшилась на 45,3\% [61]. Отмечено различное влияние на интенсивность зуда терапии средними дозами УФА-1-излучения в том же режиме 3 процедуры в неделю, но более короткими курсами в 6 недель. T. Gambichler и соавт. (2008) после курса лечения с кумулятивной дозой излучения 900 Дж/см² отметили статистически значимое уменьшение интенсивности зуда на 43,7\% [65]. Однако по данным Т. Gambichler и соавт. (2009), в результате курса УФА-1-терапии (кумулятивная доза облучения - $880 \pm 40,4$ Дж/см²) достигнуто менее выраженное уменьшение интенсивности зуда на 26,78\%, при этом не было указано, являлись ли выявленные изменения интенсивности зуда статистически значимыми [49]. Результатом УФА-1-терапии в режиме 5 раз в неделю в течение 4 недель (всего 20 процедур, кумулятивная доза не указана), проводившейся в рамках двух исследований, стало уменьшение интенсивности зуда на 47,4 и 49,0\% соответственно [66, 68]. Не было выявлено статистически значимого уменьшения интенсивности зуда после курса УФА-1-терапии средними дозами (кумулятивная доза 1000 Дж/см²) в режиме 3 раза в неделю на протяжении 4-8 недель (всего 12-24 процедуры) в исследовании, в котором приняло участие всего 9 человек, что может быть связано с малым объемом выборки, снижающим статистическую мощность исследования и вероятность обнаружить имеющиеся различия [62].

При сравнении эффрективности УФА-1-терапии с другими методами лечения была отмечена равная эффрективность средних доз УФА-1-терапии с УФБ-311 нм терапией 
[49, 61]. Описана большая эфрфективность ПУВА-терапии атопического дерматита по сравнению с УФА-1-терапией в средних дозах [50]. Сравнение эффрективности терапии высокими дозами УФА-1-излучения и наружного лечения кортикостероидами продемонстрировало превосходство УФА-1-терапии перед топическим кортикостероидом фрлуокортолоном [54].

При оценке сроков наступления терапевтического эфффекта УФА-1-терапии была продемонстрирована высокая скорость достижения улучшения состояния пациентов, которое наступало через 1 неделю при использовании средних и высоких доз УФА-1-излучения $[53,56]$.

Дизайн ряда исследований предусматривал наблюдение различной продолжительности времени за пациентами после проведенного курса фототерапии, что позволило получить данные о продолжительности ремиссии, достигнутой после проведенного курса УФА-1-терапии. В течение 1 месяца наблюдения после курса УФА-1-терапии отмечался сохраняющийся положительный эфффект лечения [52, 64]. По данным S. Tzaneva и соавт. (2001), S. Tzaneva и соавт. (2010), медиана времени, через которое происходил рецидив, составила 4 недели (межквартильный диапазон 4-12 недель) [50, 56]. A. Osmola-Mańkowska и соавт. (2014) указали, что достигнутое после курса УФА-1-терапии в средних дозах улучшение у больных атопическим дерматитом сохранялось в среднем 6,6 недели [55]. О постепенном ухудшении состояния кожи в течение 2-3 месяцев после лечения средними дозами УФА-1-излучения сообщили 24 из 32 пациентов с атопическим дерматитом, что потребовало применения антигистаминных препаратов и кортикостероидных мазей [64]. Тем не менее отмечена возможность сохранения ремиссии даже через 6 месяцев после проведенного курса УФА-1-терапии [56].

\section{Безопасность УФА-1-терапии}

Данные о развившихся у пациентов с атопическим дерматитом нежелательных явлениях УФА-1-терапии были представлены в 14 исследованиях. При этом каждое из них характеризовалось регистрацией разных нежелательных явлений.

Одним из наиболее частых нежелательных явлений УФА-1-терапии описана гиперпигментация кожи, но она была зарегистрирована только в трех исследованиях [55, $69,70]$. В двух из них отмечено, что гиперпигментация появилась у 8 из 16 пациентов с атопическим дерматитом и у 28 из 30 пациентов соответственно [69, 70]. Частым нежелательным явлением во время УФА-1-терапии была сухость кожи, иногда требовавшая использования эмолиентов. Ее развитие отмечалось у 22 из 32 пациентов и у 15 из 28 пациентов с атопическим дерматитом [64, 70]. В других исследованиях, в которых на фоне УФА-1-терапии регистрировалось возникновение сухости кожи, частота ее развития не указывалась $[53,57,63]$. У пациентов отмечалось также развитие эритемы $[49,50,55,56$, 68, 69]. Ho S. Tzaneva и соавт. (2001) охарактеризовали эритему как редкое нежелательное явление УФА-1-терапии [56]. Обострение атопического дерматита во время УФА-1-терапии высокими дозами было зарегистрировано у 5 из 11 пациентов, что потребовало дополнительного назначения топических кортикостероидов [59].

Пациенты отмечали во время процедур УФА-1-терапии ощущение жара или избыточного тепла [50, 53, 55,
56, 60]. При этом если S. Tzaneva и соавт. (2001), использовавшие для лечения пациентов средние и высокие дозы УФА-1-излучения, отмечали, что ощущение жара у пациентов развивалось редко, но было болезненным, то в исследовании И.Н. Авдиенко и А.А. Кубанова (2009), применявших низкие дозы УФА-1-излучения, наоборот, отмечено, что ощущение жара развивалось у большинства пациентов, но было слабо выраженным [56, 60]. Ощущение жжения возникало у 7 из 23 пациентов и у 5 из 36 пациентов, получавших лечение методом УФА-1-терапии $[50,68]$. Зуд также был отмечен как нежелательное явление УФА-1-терапии [51, 52, 55, 57, 64, 69]. Частота его развития существенно варьировала от 10 до 68,75\% $[51,64]$. Во время проведения процедур УФА-1-терапии отмечались также усиление потоотделения и общий дискомфрорт, наблюдавшиеся у 10\% пациентов $[5,1,52]$.

В единичных случаях регистрировались пиодермия лица (у 1 пациента из 50) и фолликулиты (у 1 пациента из 23) [50, 51].

Отмечены случаи прекращения курса УФА-1-терапии из-за развития нежелательных явлений. G. von Kobyletzki и соавт. (1999) указали, что развитие нежелательных явлений стало причиной прекращения лечения методом УФА-1-облучения кожи 10\% пациентов с атопическим дерматитом [51]. Этими нежелательными явлениями, зарегистрированными у 5 пациентов из 50 получавших лечение, были в 4 случаях - зуд, повышенное потоотделение, общий дискомфорт во время процедуры, в одном случае - прогрессирование пиодермии лица. В Корее из 16 пациентов, которым проводилась УФА-1-терапия, двое прекратили лечение из-за увеличения выраженности эритемы и зуда [69].

Лишь в одном исследовании была отмечена неэффрективность УФА-1-терапии больных атопическим дерматитом. Лечение было неэффективным у 4 из 23 пациентов, получавших лечение средними дозами УФА-1-излучения (70 Дж/см²) [50]. В 7 исследованиях не указано, развивались ли у пациентов нежелательные явления [54, 58, 60-62, 65, 66].

\section{Обсуждение}

Имеющиеся данные демонстрируют эффрективность УФА-1-терапии в лечении больных атопическим дерматитом средней и тяжелой степени тяжести, несмотря на использование различных режимов терапии. Результаты сравнительных исследований показали, что оптимальными для лечения больных атопическим дерматитом следует считать средние дозы УФА-1-излучения (>20-70 Дж/см² по европейской классификации). По своей эфффективности они не отличаются от высоких доз и превосходят низкие дозы УФА-1-излучения [56, 58]. В то же время получены данные о высокой эффрективности комбинации низких доз УФА-1-терапии и лекарственной системной и наружной терапии. Нельзя исключить, что в комплекс лекарственной терапии, которая сопровождает УФА-1-терапию, могут входить препараты, обладающие фотосенсибилизирующим действием, повышающие чувствительность к ультрафиолетовым лучам и, соответственно, повышающие эффрективность фототерапии. В число таких лекарственных препаратов включают часто использующиеся для лечения больных атопическим дерматитом антигистаминные препараты и топические кортикостероиды [71].

Полученные данные указывают на возможное влияние фрототипа кожи на эффрективность УФА-1-терапии 
в различных дозах. Терапия средними дозами УФА-1-излучения была эффективной только для пациентов с I и || фототипами кожи, но не для пациентов с III и IV фоототипами, в отличие от высоких доз УФА-1-излучения, которые были эффрективны для лечения больных и с I-II, и c III-IV фототипами кожи [57]. Эти данные согласуются с результатами оценки влияния фототипа кожи на величину минимальной эритемной дозы УФА-1-излучения, согласно которой существует корреляция между фототипом кожи и минимальной эритемной дозой УФА-1-излучения. Обнаружено, что минимальная эритемная доза составляла для I, II, III и IV фоототипов кожи 22, 42, 86 и 100 Дж/см² соответственно [72]. Однако M. Welti и соавт. (2020) не обнаружили такой корреляции между минимальной эритемной дозой УФА-1-излучения и фототипом кожи [73]. Такое противоречие требует продолжения исследований зависимости минимальной эритемной дозы УФА-1-излучения и эффективности УФА-1-терапии больных атопическим дерматитом от фототипа кожи.

Важным признаком атопического дерматита, наиболее значимо снижающим качество жизни пациентов, является зуд. Хотя влияние УФА-1-терапии на интенсивность зуда оценивалось лишь в небольшом числе исследований, проведенные исследования продемонстрировали ее эфффективность в уменьшении интенсивности зуда.

Первоначально терапия методом УФА-1 проводилась в ежедневном режиме. Однако в последующем при определении минимальных эритемогенных доз было показано, что в зависимости от фототипа кожи и облучаемого участка эритема может возникать спустя 4-8 часов после облучения. С учетом времени, которое эта эритема может сохраняться, было сделано предположение, что режим ежедневных УФА-1-облучений несет в себе риск развития со временем кумулятивной эритемы [74]. В последующем для терапии больных атопическим дерматитом использовались режимы УФА-1-облучения 3-5 процедур в неделю.

УФА-1-терапия показала себя как безопасный метод лечения больных атопическим дерматитом. Указано, что УФА-1-терапия хорошо переносится пациентами и может назначаться даже при обострениях атопического дерматита, сопровождающихся яркой эритемой $[54,59]$.

Наиболее характерным нежелательным явлением УФА-1-терапии является ощущение пациентами избыточного тепла и жара во время проведения процедур, поскольку процедуры УФА-1-терапии характеризуются существенным выделением тепла люминесцентными или металлогалогеновыми источниками УФА-1-излучения. Развитие этих нежелательных явлений УФА-1-терапии обусловлено длительным временем воздействия низкоэнергетического УФА-1-излучения, необходимым для проявления его биологического эффекта [34]. Процедура УФА-1-терапии в зависимости от применяемой дозы может занимать от 30 минут до 1 часа или более, в отличие от терапии с использованием UVB-излучения или PUVA-терапии, которые требуют гораздо более короткого времени воздействия, длящегося секунды или минуты [30, 34]. В связи с этим современные аппараты для УФА-1-терапии оборудуют системами кондиционирования, предназначенными для охлаждения воздуха в кабине.

Зуд и гиперпигментацию также относят к частым нежелательным явлениям УФА-1-терапии [30, 75-77]. Гиперпигментация бывает наиболее выражена на участках ранее пораженной кожи [30]. Возможно развитие эритемы [30]. Не исключается активация герпетической инфекции или индукция фотодерматозов [34, 78]. Отмечена развития на фоне УФА-1-терапии обострения атопического дерматита или увеличения сухости кожи, но в таких случаях было продолжить фототерапию, назначив дополнительно топические кортикостероиды или эмолиенты. У $3 \%$ больных атопическим дерматитом обнаружена фоточувствительность, препятствующая проведению фототерапии [79].

Серьезные нежелательные явления УФА-1-терапии, требовавшие прекратить лечение, наблюдались редко. Чаще всего причиной прекращения лечения была невозможность для пациента продолжать лечение из-за общего дискомфорта во время процедуры - повышенного потоотделения, усиления зуда, а также из-за усиления эритемы $[51,69]$. Кроме того, причиной отмены курса УФА-1-терапии было развитие пиодермии [51].

Убедительные данные о наличии или отсутствии у УФА-1-излучения канцерогенных свойств отсутствуют, в связи с чем пациентам, получающим УФА-1-терапию, следует рекомендовать избегать посещения соляриев и избыточного воздействия естественного солнечного света, пока не будет определена величина этого риска [30]. Пациентам, получающим курсы УФА-1-терапии, показано регулярное проведение полного осмотра кожи для выявления ее новообразований.

В редких случаях УФА-1-терапия больных атопическим дерматитом может быть неэффективной. Было показано, что терапевтический ответ на УФА-1-терапию значительно менее выражен у больных атопическим дерматитом с высоким уровнем общего и аллерген-специфических IgE в сыворотке крови, которые, как предполагается, плохо переносят повышение потоотделения во время терапевтических процедур [52, 80]. Кроме того, эффрективность УФА-1-терапии может уменьшать высокая плотность колонизации кожи золотистым стафилококком [80]. У людей, у которых была неэфрфективной УФА-1-терапия, часто высевалась кишечная Candida albicans [80].

При назначении УФА-1-терапии следует учитывать противопоказания к ее назначению. К ним относятся нарушения фооточувствительности (например, пигментная ксеродерма, порфирия), прием фотосенсибилизирующих препаратов, наличие злокачественных новообразований кожи в анамнезе (меланома и немеланомный рак кожи), длительная иммуносупрессия (например, после трансплантации органов) и лучевая терапия в анамнезе. Установлено, что воздействие азатиоприна в сочетании с УФА-1-излучением повышает риск развития повреждения ДНК и развития рака кожи $[30,81]$. В связи с этим перед началом курса УФА-1-терапии необходимо тщательно оценить анамнез пациента, включая фототип кожи, чувствительность к воздействию солнца и наличие в анамнезе злокачественных новообразований кожи. В частности, необходимо исключить прием пациентом потенциальных фототоксических и фотоаллергических препаратов и наличие у него фотодерматозов. Не следует сочетать с УФА-1-терапией лечение иммунодепрессантами, например азатиоприном $[34,82]$. В связи с тем, что на фоне фототерапии повышается риск развития лимфом и новообразований кожи во время лечения циклоспорином [83], не следует проводить комбинированное лечение методом УФА-1-терапии и циклоспорином. 
Несмотря на то что проведенные исследования демонстрируют эффрективность УФА-1-терапии больных атопическим дерматитом, дизайн большинства из них не позволил оценить ряд важных показателей эфрективности терапии, что требует их дальнейшего изучения. К этим показателям относятся скорость наступления терапевтического эффекта, длительность его сохранения, что позволит рассчитать продолжительность необходимого курса лечения. Эфрфективность УФА-1-терапии больных атопическим дерматитом демонстрировалась как процентное уменьшение значения показателя степени тяжести болезни в конце курса терапии по сравнению с исходным значением. Тем не менее, чтобы получить возможность сопоставлять эфффективность УФА-1-терапии с эффрективностью других методов лечения больных атопическим дерматитом, необходима оценка таких широко используемых в настоящее время показателей, как SCORAD50, SCORAD75 и EASI50, EASI75, отражающих долю больных, у которых степень тяжести атопического дерматита в процессе лечения уменьшилась соответственно на 50\% и более и на $75 \%$ и более. При этом необходимо оценивать не только динамику степени тяжести атопического дерматита, но и интенсивность его важнейшего признака - зуда. Представляется, что эффрективность УФА-1-терапии может быть оценена только в случае отсутствия сопутствующей лекарственной терапии. Кроме того, в ранее проведенных исследованиях оценивались лишь некоторые нежелательные явления. Представляется необходимым для оценки безопасности УФА-1-терапии тщательный учет любых развивающихся нежелательных явлений как легких, так и серьезных, требующих отмены лечения.

\section{Заключение}

УФА-1-терапия является эфрфективным и безопасным методом терапии больных атопическим дерматитом средней и тяжелой степени тяжести. Эфрфективность УФА-1-терапии больных атопическим дерматитом проявляется достаточно быстро и может стать заметной уже через одну неделю лечения. При назначении УФА-1-терапии следует учитывать имеющиеся противопоказания, а также неудобства ее применения - длительность процедур, которая может достигать 1 часа и более, что требует длительного пребывания пациентов в условиях нагревающего микроклимата. Тем не менее оптимальный режим проведения УФА-1-терапии больным атопическим дерматитом до конца не определен, что требует проведения соответствующих исследований.

\section{Литература/References}

1. Werfel T, Allam JP, Biedermann T, Eyerich K, Gilles S, GuttmanYassky $E$, et al. Cellular and molecular immunologic mechanisms in patients with atopic dermatitis. J Allergy Clin Immunol. 2016;138(2):336349. doi: 10.1016/j.jaci.2016.06.010

2. Biedermann T, Skabytska Y, Kaesler S, Volz T. Regulation of T cell immunity in atopic dermatitis by microbes: The Yin and Yang of cutaneous inflammation. Front Immunol. 2015;13;6:353.

doi: 10.3389/fimmu.2015.00353

3. Langan SM, Irvine AD, Weidinger S. Atopic dermatitis. Lancet. 2020;396(10247):345-360. doi: 10.1016/S0140-6736(20)31286-1

4. Luger $T$, Amagai $M$, Dreno B, Dagnelie MA, Liao W, Kabashima K, et al. Atopic dermatitis: Role of the skin barrier, environment, microbiome, and therapeutic agents. J Dermatol Sci. 2021;102(3):142-157. doi: 10.1016/j.jdermsci.2021.04.007

5. Leung DY, Bhan AK, Schneeberger EE, Geha RS. Characterization of the mononuclear cell infiltrate in atopic dermatitis using monoclonal antibodies. J Allergy Clin Immunol. 1983;71(1 Pt 1):47-56.

doi: 10.1016/0091-6749(83)90546-8

6. Leung DY, Guttman-Yassky E. Deciphering the complexities of atopic dermatitis: shifting paradigms in treatment approaches. J Allergy Clin Immunol. 2014;134(4):769-779. doi: 10.1016/j.jaci.2014.08.008

7. Hamid Q, Boguniewicz M, Leung DY. Differential in situ cytokine gene expression in acute versus chronic atopic dermatitis. J Clin Invest. 1994:94:870-876. doi: 10.1172/JCl117408

8. Hamid Q, Naseer T, Minshall EM, Song YL, Boguniewicz M, Leung DY. In vivo expression of $\mathrm{IL}-12$ and $\mathrm{IL}-13$ in atopic dermatitis. J Allergy Clin Immunol. 1996;98(1):225-231.

doi: 10.1016/s0091-6749(96)70246-4

9. Czarnowicki T, Krueger JG, Guttman-Yassky E. Skin barrier and immune dysregulation in atopic dermatitis: an evolving story with important clinical implications. J Allergy Clin Immunol Pract. 2014;2(4):371-379. doi: 10.1016/j.jaip.2014.03.006
10. Oliva M, Renert-Yuval Y, Guttman-Yassky E. The 'omics' revolution: redefining the understanding and treatment of allergic skin diseases. Curr Opin Allergy Clin Immunol. 2016;16(5):469-476. doi: $10.1097 / \mathrm{ACl} .0000000000000306$

11. Gittler JK, Shemer A, Suárez-Fariñas M, Fuentes-Duculan J, Gulewicz KJ, Wang $C Q$, et al. Progressive activation of $T(H) 2 / T(H) 22$ cytokines and selective epidermal proteins characterizes acute and chronic atopic dermatitis. J Allergy Clin Immunol. 2012;130(6):1344-1354. doi: 10.1016/j.jaci.2012.07.012

12. Dhingra N, Guttman-Yassky E. A possible role for IL-17A in establishing Th2 inflammation in murine models of atopic dermatitis. J Invest Dermatol. 2014;134(8):2071-2074. doi: 10.1038/jid.2014.141

13. Thepen T, Langeveld-Wildschut EG, Bihari IC, van Wichen DF, van Reijsen FC, Mudde GC, et al. Biphasic response against aeroallergen in atopic dermatitis showing a switch from an initial TH2 response to a TH1 response in situ: an immunocytochemical study. J Allergy Clin Immunol. 1996;97(3):828-837. doi: 10.1016/s0091-6749(96)80161-8

14. Drislane C, Irvine AD. The role of filaggrin in atopic dermatitis and allergic disease. Ann Allergy Asthma Immunol. 2020;124(1):36-43. doi: 10.1016/j.anai.2019.10.008

15. Danso MO, van Drongelen V, Mulder A, van Esch J, Scott H, van Smeden J, et al. TNF-alpha and Th2 cytokines induce atopic dermatitis-like features on epidermal differentiation proteins and stratum corneum lipids in human skin equivalents. J Invest Dermatol. 2014;134(7):1941-1950. doi: 10.1038/jid.2014.83

16. Kim BE, Leung DY, Boguniewicz M, Howell MD. Loricrin and involucrin expression is down-regulated by Th2 cytokines through STAT-6. Clin Immunol. 2008;126(3):332-337. doi: 10.1016/j.clim.2007.11.006

17. Gutowska-Owsiak D, Schaupp AL, Salimi M, Selvakumar TA, McPherson T, Taylor S, et al. IL-17 downregulates filaggrin and affects keratinocyte expression of genes associated with cellular adhesion. Exp Dermatol. 2012;21(2):104-110. doi: 10.1111/j.1600-0625.2011.01412.x 
18. Howell MD, Kim BE, Gao P, Grant AV, Boguniewicz M, Debenedetto $\mathrm{A}$, et al. Cytokine modulation of atopic dermatitis filaggrin skin expression. J Allergy Clin Immunol. 2007;120(1):150-155.

doi: 10.1016/j.jaci.2007.04.031

19. Egawa G, Kabashima K. Multifactorial skin barrier deficiency and atopic dermatitis: Essential topics to prevent the atopic march. J Allergy Clin Immunol. 2016;138(2):350-358. doi: 10.1016/j.jaci.2016.06.002

20. Sehra S, Yao Y, Howell MD, Nguyen ET, Kansas GS, Leung DY, et al. IL-4 regulates skin homeostasis and the predisposition toward allergic skin inflammation. J Immunol. 2010;184(6):3186-3190. doi: 10.4049/jimmunol.0901860

21. Gutowska-Owsiak D, Schaupp AL, Salimi M, Taylor S, Ogg GS. Interleukin-22 downregulates filaggrin expression and affects expression of profilaggrin processing enzymes. Br J Dermatol. 2011;165(3):492-498. doi: 10.1111/j.1365-2133.2011.10400.x

22. Ouyang W, Rutz S, Crellin NK, Valdez PA, Hymowitz SG. Regulation and functions of the IL-10 family of cytokines in inflammation and disease. Annu Rev Immunol. 2011;29:71-109.

doi: 10.1146/annurev-immunol-031210-101312

23. Saraiva M, O'Garra A. The regulation of IL-10 production by immune cells. Nat Rev Immunol. 2010;10(3):170-181. doi: 10.1038/nri2711

24. Brandt EB, Sivaprasad U. Th2 Cytokines and Atopic Dermatitis. J Clin Cell Immunol. 2011:2(3):110. doi: 10.4172/2155-9899.1000110

25. Darling AR, Freyschmidt EJ, Burton OT, Koleoglou KJ, Oyoshi MK, Oettgen HC. IL-10 suppresses IL-17-mediated dermal inflammation and reduces the systemic burden of vaccinia virus in a mouse model of eczema vaccinatum. Clin Immunol. 2014;150(2):153-160. doi:10.1016/j.clim.2013.11.010

26. Niwa Y. Elevated RANTES levels in plasma or skin and decreased plasma IL-10 levels in subsets of patients with severe atopic dermatitis. Arch Dermatol. 2000;136(1):125-126. doi: 10.1001/archderm.136.1.125

27. Seneviratne SL, Jones L, Bailey AS, Black AP, Ogg GS. Severe atopic dermatitis is associated with a reduced frequency of IL-10 producing allergen-specific CD4+ T cells. Clin Exp Dermatol. 2006;31(5):689-694. doi: 10.1111/j.1365-2230.2006.02172.x

28. Dunstan JA, Hale J, Breckler L, Lehmann $H$, Weston S, Richmond $\mathrm{P}$, et al. Atopic dermatitis in young children is associated with impaired interleukin-10 and interferon-gamma responses to allergens, vaccines and colonizing skin and gut bacteria. Clin Exp Allergy. 2005;35(10):1309-1317. doi: 10.1111/j.1365-2222.2005.02348.x

29. Oh SH, Park CO, Wu WH, Kim JY, Jin S, Byamba D, et al. Corticotropin-releasing hormone downregulates IL-10 production by adaptive forkhead box protein 3-negative regulatory $T$ cells in patients with atopic dermatitis. J Allergy Clin Immunol. 2012;129(1):151-159.

doi: 10.1016/j.jaci.2011.09.008

30. York NR, Jacobe HT. UVA1 phototherapy: a review of mechanism and therapeutic application. Int J Dermatol. 2010;49(6):623-630. doi: 10.1111/j.1365-4632.2009.04427.x

31. Singer S, Berneburg M. Phototherapie. J Dtsch Dermatol Ges. 2018;16(9):1120-1131. doi: 10.1111/ddg.13646_g

32. Vieyra-Garcia PA, Wolf P. A deep dive into UV-based phototherapy: Mechanisms of action and emerging molecular targets in inflammation and cancer. Pharmacol Ther. 2021;222:107784.

doi: 10.1016/j.pharmthera.2020.107784

33. Mutzhas MF, Holzle E, Hofmann C, Plewig G. A new apparatus with high radiation energy between 320-460 nm: physical description and dermatological applications. J Invest Dermatol. 1981;76(1):42-47. doi: 10.1111/1523-1747.ep12524813

34. Gambichler T, Terras S, Kreuter A. Treatment regimens, protocols, dosage, and indications for UVA1 phototherapy: Facts and controversies. Clin Dermatol. 2013;31(4):438-454. doi: 10.1016/j.clindermatol.2013.01.011

35. Plewig G, Hofmann C, Braun-Falco 0, Nath G, Kreitmair A. A new apparatus for the delivery of high intensity UVA and UVA+UVB irradiation, and some dermatological applications. Br J Dermatol. 1978;98(1):15-24. doi: 10.1111/j.1365-2133.1978.tb07328.x
36. Krutmann J. Phototherapy for atopic dermatitis. Clin Exp Dermatol. 2000;25(7):552-558. doi: 10.1046/j.1365-2230.2000.00700.x

37. Gambichler T, Majert J, Pljakic A, Rooms I, Wolf P. Determination of the minimal erythema dose for ultraviolet $\mathrm{A} 1$ radiation. Br J Dermatol. 2017;177(1):238-244. doi: 10.1111/bjd.15245

38. Grabbe J, Welker P, Humke S, Grewe M, Schöpf E, Henz BM, Krutmann J. High-dose ultraviolet A1 (UVA1), but not UVA/UVB therapy, decreases IgE-binding cells in lesional skin of patients with atopic eczema. J Invest Dermatol. 1996;107(3):419-422. doi: 10.1111/1523-1747.ep12363402

39. Besaratinia A, Kim SI, Bates SE, Pfeifer GP. Riboflavin activated by ultraviolet A1 irradiation induces oxidative DNA damage-mediated mutations inhibited by vitamin C. Proc Natl Acad Sci USA. 2007;104(14):5953-5958. doi: 10.1073/pnas.0610534104

40. Godar DE. UVA1 radiation triggers two different final apoptotic pathways. J Invest Dermatol. 1999;112(1):3-12.

doi: 10.1046/j.1523-1747.1999.00474.x

41. Guhl S, Hartmann K, Tapkenhinrichs S, Smorodchenko A, Grützkau A, Henz BM, Zuberbier T. Ultraviolet irradiation induces apoptosis in human immature, but not in skin mast cells. J Invest Dermatol. 2003;121(4):837-844. doi: 10.1046/j.1523-1747.2003.12480.x

42. Новиков В.Е., Левченкова О.С. Митохондриальные мишени для фармакологической регуляции адаптации клетки к воздействию гипоксии. Обзоры по клинической фармакологии и лекарственной терапии. 2014;12(2):28-35. [Novikov VE, Levchenkova OS. Mitochondrial targets for pharmacological regulation of cell adaptation to hypoxia. Reviews on Clinical Pharmacology and Drug Therapy. 2014;12(2):28-35 (In Russ.)]

43. Godar DE. Preprogrammed and programmed cell death mechanisms of apoptosis: UV-induced immediate and delayed apoptosis. Photochem Photobiol. 1996;63(6):825-830. doi: 10.1111/j.1751-1097.1996.tb09638.x

44. Tyrrell R.M. Ultraviolet radiation and free radical damage to skin. Biochem Soc Symp. 1995;61:47-53. doi: 10.1042/bss0610047

45. Skov L, Hansen H, Allen M, Villadsen L, Norval M, Barker JN, et al. Contrasting effects of ultraviolet $A 1$ and ultraviolet $B$ exposure on the induction of tumour necrosis factor-alpha in human skin. $\mathrm{Br} \mathrm{J}$ Dermatol. 1998;138(2):216-220. doi: 10.1046/j.1365-2133.1998.02063.x

46. Krutmann J, Grewe M. Involvement of cytokines, DNA damage, and reactive oxygen intermediates in ultraviolet radiation-induced modulation of intercellular adhesion molecule-1 expression. J Invest Dermatol. 1995;105(1 Suppl):67S-70S. doi: 10.1111/1523-1747.ep12316095

47. Szegedi A, Simics E, Aleksza M, Horkay I, Gaál K, Sipka S, et al. Ultraviolet-A1 phototherapy modulates Th1/Th2 and Tc1/Tc2 balance in patients with systemic lupus erythematosus. Rheumatology (0xford). 2005;44(7):925-931. doi: 10.1093/rheumatology/keh643

48. Grewe M, Gyufko K, Krutmann J. Interleukin-10 production by cultured human keratinocytes: regulation by ultraviolet $B$ and ultraviolet $A 1$ radiation. J Invest Dermatol. 1995;104(1):3-6. doi: 10.1111/1523-1747.ep12613446

49. Gambichler T, Othlinghaus N, Tomi NS, Holland-Letz T, Boms S, Skrygan M, et al. Medium-dose ultraviolet (UV) A1 vs. narrowband UVB phototherapy in atopic eczema: a randomized crossover study. $\mathrm{Br} J$ Dermatol 2009;160(3):652-658. doi: 10.1111/j.1365-2133.2008.08984.x

50. Tzaneva S, Kittler H, Holzer G, Reljic D, Weber M, Hönigsmann H, Tanew A. 5-Methoxypsoralen plus ultraviolet (UV) A is superior to mediumdose UVA1 in the treatment of severe atopic dermatitis: A randomized crossover trial. Br J Dermatol. 2010;162(3):655-660.

doi: 10.1111/j.1365-2133.2009.09514.x

51. von Kobyletzki G, Pieck C, Hoffmann K, Freitag M, Altmeyer P. Medium-dose UVA1 cold-light phototherapy in the treatment of severe atopic dermatitis. J Am Acad Dermatol. 1999;41(6):931-937. doi: 10.1016/s0190-9622(99)70249-5

52. von Kobyletzki G, Freitag M, Herde M, Höxtermann S, Stücker M, Hoffmann K, Altmeyer P. Phototherapie bei schwerer atopischer Dermatitis. Vergleich zwischen herkömmlicher UVA1-Therapie, UVA1-Kaltlicht- und kombinierter UVA-UVB-Therapie. Hautarzt. 1999;50(1):27-33. doi: $10.1007 / s 001050050860$ 
53. Krutmann J, Czech W, Diepgen T, Niedner R, Kapp A, Schöpf E. High-dose UVA1 therapy in the treatment of patients with atopic dermatitis. J Am Acad Dermatol. 1992;26(2 Pt 1):225-230.

doi: 10.1016/0190-9622(92)70031-a

54. Krutmann J, Diepgen TL, Luger TA, Grabbe S, Meffert H, Sönnichsen $N$, et al. High-dose UVA1 therapy for atopic dermatitis: Results of a multicenter trial. J Am Acad Dermatol. 1998;38(4):589-593. doi: 10.1016/s0190-9622(98)70123-9

55. Osmola-Ma kowska A, Pola ska A, Silny W, aba R, Adamski Z, Da czak-Pazdrowska A. Topical tacrolimus vs medium-dose ultraviolet A1 phototherapy in the treatment of atopic dermatitis - a preliminary study in relation to parameters of the epidermal barrier function and high-frequency ultrasonography. Eur Rev Med Pharmacol Sci. 2014;18(24):3927-3934.

56. Tzaneva S, Seeber A, Schwaiger M, Hönigsmann H, Tanew A. High-dose versus medium-dose UVA1 phototherapy for patients with severe generalized atopic dermatitis. J Am Acad Dermatol. 2001;45(4):503-507. doi: $10.1067 / \mathrm{mjd} .2001 .114743$

57. Pacifico A, lacovelli P, Damiani G, Ferraro C, Cazzaniga S, Conic $R R$, et al. 'High dose' vs. 'medium dose' UVA1 phototherapy in italian patients with severe atopic dermatitis. J Eur Acad Dermatol Venereol. 2019;33(4):718-724. doi: 10.1111/jdv.15362

58. Kowalzick L, Kleinheinz A, Weichenthal M, Neuber K, Köhler I, Grosch J, et al. Low dose versus medium dose UV-A1 treatment in severe atopic dermatitis. Acta Derm Venereol. 1995; 75 (1): 43-45. doi: 10.2340/00015555754345

59. Dittmar HC, Pflieger D, Schopf E, Simon JC. UVA1-Phototherapie. Pilotstudie zur Dosisfindung bei der bei akut exazerbierten atopischen Dermatitis. Hautarzt. 2001;52(5):423-427. doi: 10.1007/s001050051336

60. Бакулев А.Л., Платонова А.Н. Отдаленные результаты применения УФА-1-терапии в комплексном лечении атопического дерматита. Бюллетень медицинских интернет-конференций (ISSN 2224-6150) 2013;3(6):961-963. [Bakulev AL, Platonova AN. Long-term results of usage of UVA-1-therapy in complex treatment of atopic dermatitis. Bulletin of Medical Internet Conferences. 2013;3(6):961-963 (In Russ.)]

61. Majoie IM, Oldhoff JM, van Weelden $H$, Laaper-Ertmann M, Bousema MT, Sigurdsson V, et al. Narrowband ultraviolet B and mediumdose ultraviolet $A 1$ are equally effective in the treatment of moderate to severe atopic dermatitis. J Am Acad Dermatol. 2009;60(1):77-84. doi: 10.1016/j.jaad.2008.08.048

62. Legat FJ, Hofer A, Brabek E, Quehenberger F, Kerl H, Wolf $P$. Narrowband UV-B vs medium-dose UV-A1 phototherapy in chronic atopic dermatitis. Arch Dermatol. 2003;139:223-224. doi: 10.1001/archderm.139.2.223

63. Олисова 0.Ю., Владимиров В.В., Мураховская Е.К. Фототерапия атопического дерматита УФА-лучами 370 нм. Российский журнал кожных и венерических болезней. 2013;6:22-27. [Olisova OYu, Vladimirov VV, Murakhovskaya EK. UVA $370 \mathrm{~nm}$ phototherapy of atopic dermatitis. Russian Journal of Skin and Venereal Diseases. 2013;6:22-27 (In Russ.)]

64. Abeck D, Schmidt T, Fesq H, Strom K, Mempel M, Brockow K, et al. Long-term efficacy of medium-dose UVA1 phototherapy in atopic dermatitis. J Am Acad Dermatol. 2000;42(2 Pt 1):254-257. doi: 10.1016/S0190-9622(00)90134-8

65. Gambichler T, Kreuter A, Tomi NS, Othlinghaus N, Altmeyer $P$, Skrygan M. Gene expression of cytokines in atopic eczema before and after ultraviolet A1 phototherapy. Br J Dermatol. 2008;158(5):1117-1120. doi: 10.1111/j.1365-2133.2008.08498.x

66. Bogaczewicz J, Malinowska K, Sysa-Jedrzejowska A, Wozniacka A. Medium-dose ultraviolet A1 phototherapy improves SCORAD index and increases mRNA expression of interleukin-4 without direct effect on human defensin-1, interleukin-10, and interleukin-31. Int $J$ Dermatol. 2016;55(7):e380-e385. doi: 10.1111/ijd.13213
67. Bogaczewicz J, Malinowska K, Sysa-Jedrzejowska A, Wozniacka A. Medium-dose ultraviolet A1 phototherapy and mRNA expression of TSLP, TARC, IL-5, and IL-13 in acute skin lesions in atopic dermatitis. Int J Dermatol. 2016;55(8):856-863. doi: 10.1111/ijd.12992

68. Malinowska K, Wozniacka A, Bogaczewicz J. The impact of medium dose UVA1 phototherapy on pruritus, DLQI and SCORAD index in patients with atopic dermatitis. Postepy Dermatol Alergol. 2020;37(6):962967. doi: 10.5114/ada.2019.88465

69. Park JB, Jang JY, Kwon DI, Seong SH, Suh KS, Jang MS. The effectiveness of high-dose ultraviolet A-1 phototherapy for acute exacerbation of atopic dermatitis in Asians. Photodermatol Photoimmunol Photomed. 2020;36(4):263-270. doi: 10.1111/phpp.12546

70. Авдиенко И.Н., Кубанов А.А. Эффрективность дальней длинноволновой ультрафиолетовой терапии у больных атопическим дерматитом. Вестник дерматологии и венерологии. 2009;3:61-63. [Avdienko IN, Kubanov AA. Efficiency of long-wave ultraviolet therapy in patients with atopic dermatitis. Vestnik Dermatologii i Venerologii. 2009;3:61-63 (In Russ.)]

71. Tajima T, Ibe M, Matsushita T, Kamide R. A variety of skin responses to ultraviolet irradiation in patients with atopic dermatitis. J Dermatol Sci. 1998;17(2):101-107. doi: 10.1016/s0923-1811(97)00080-7

72. Valbuena Mesa MC, Nova Villanueva JA, Sánchez Vanegas G. Minimal erythema dose: Correlation with Fitzpatrick skin type and concordance between methods of erythema assessment in a patient sample in Colombia. Actas Dermosifiliogr (Engl Ed). 2020;111(5):390-397. doi: 10.1016/j.ad.2019.12.003

73. Welti M, Ramelyte E, Dummer R, Imhof L. Evaluation of the minimal erythema dose for UVB and UVA in context of skin phototype and nature of photodermatosis. Photodermatol Photoimmunol Photomed. 2020;36(3):200-207. doi: 10.1111/phpp.12537

74. Beattie PE, Dawe RS, Ferguson J, Ibbotson SH. Dose-response and time-course characteristics of UV-A1 erythema. Arch Dermatol. 2005;141(12):1549-1555. doi: 10.1001/archderm.141.12.1549

75. Kroft EB, Berkhof NJ, van de Kerkhof PC, Gerritsen RM, de Jong EM. Ultraviolet A phototherapy for sclerotic skin diseases: a systematic review. J Am Acad Dermatol. 2008;59(6):1017-1030. doi: 10.1016/j.jaad.2008.07.042

76. Gambichler T. Management of atopic dermatitis using photo(chemo) therapy. Arch Dermatol Res. 2009;301(3):197-203. doi: 10.1007/s00403-008-0923-5

77. Dawe RS. Ultraviolet A1 phototherapy. Br J Dermatol. 2003;148(4):626-637. doi: 10.1046/j.1365-2133.2003.05261.x

78. Gambichler T, Al-Muhammadi R, Boms S. Immunologically mediated photodermatoses: diagnosis and treatment. Am J Clin Dermatol. 2009;10(3):169-180. doi: 10.2165/00128071-200910030-00003

79. ten Berge 0, van Weelden H, Bruijnzeel-Koomen CA, de BruinWeller MS, Sigurdsson V. Throwing a light on photosensitivity in atopic dermatitis: a retrospective study. Am J Clin Dermatol. 2009;10(2):119-123. doi: 10.2165/00128071-200910020-00004

80. Schempp CM, Effinger T, Czech W, Krutmann J, Simon JC, Schöpf E. Charakterisierung von Non-Respondern bei der hochdosierten UVA1-Therapie der akut exazerbierten Atopischen Dermatitis. Hautarzt. 1997:48(2):94-99. doi: 10.1007/s001050050552

81. Brem R, Daehn I, Karran P. Efficient DNA interstrand crosslinking by 6-thioguanine and UVA radiation. DNA Repair (Amst). 2011;10(8):869876. doi: 10.1016/j.dnarep.2011.05.010

82. Brem R, Karran P. Multiple forms of DNA damage caused by UVA photoactivation of DNA 6-thioguanine. Photochem Photobiol. 2011;88(1):513. doi: 10.1111/j.1751-1097.2011.01043.x

83. Amber T, Tabassum S. Cyclosporin in dermatology: A practical compendium. Dermatol Ther. 2020;33(6):e13934. doi: 10.1111/dth.13934 
Участие авторов: все авторы внесли существенный вклад в проведение поисково-аналитической работы и подготовку статьи, прочли и одобрили финальную версию до публикации.

Концепция и дизайн статьи, одобрение окончательной версии статьи - А.А. Кубанов; анализ литературы, сбор и обработка материала, написание текста статьи - В.В. Чикин; концепция, дизайн, подготовка текста статьи - А.Э. Карамова; анализ литературы, сбор материала — Л.Х. Давлетбаева.

Authors' participation: all authors made a significant contribution to the search and analytical work and preparation of the article, read and approved the final version before publication.

Concept and design, final approving the article - Alexey A. Kubanov; literature analysis, data collection, analysis, and interpretation, writing an article — Vadim V. Chikin; concept and design development, data analysis and interpretation, writing an article — Arfenya E. Karamova; literature analysis, data collection — Liaisan K. Davletbaeva.

\section{Информация об авторах}

*Чикин Вадим Викторович - д.м.н.; адрес: Россия, 107076, Москва, улица Короленко, д. 3, стр. 6; ORCID iD: https://orcid.org/0000-0002-9688-2727; eLibrary SPIN: 3385-4723; e-mail: chikin@cnikvi.ru

Кубанов Алексей Алексеевич - д.м.н., профессор, член-корреспондент PAH; ORCID iD: https://orcid.org/0000-0002-7625-0503; eLibrary SPIN: 8771-4990; e-mail: alex@cnikvi.ru

Карамова Арфеня Эдуардовна — к.м.н.; ORCID iD: https://orcid.org/0000-0003-3805-8489; eLibrary SPIN: 3604-6491; e-mail: karamova@cnikvi.ru

Давлетбаева Ляйсан Халиловна — ORCID iD: https://orcid.org/0000-0003-4952-0800; e-mail: lesya-g|@mail.ru

\section{Information about the authors}

*Vadim V. Chikin — MD, Dr. Sci. (Med.); address: 3 bldg 6, Korolenko street, 107076 Moscow, Russia; ORCID iD: https://orcid.org/0000-0002-9688-2727; eLibrary SPIN: 3385-4723; e-mail: chikin@cnikvi.ru

Alexey A. Kubanov - MD, Dr. Sci. (Med.), Professor, Corresponding Member of the Russian Academy of Sciences; ORCID iD: https://orcid.org/0000-0002-7625-0503; eLibrary SPIN: 8771-4990; e-mail: alex@cnikvi.ru

Arfenya E. Karamova - MD, Cand. Sci. (Med.); ORCID iD: https://orcid.org/0000-0003-3805-8489; eLibrary SPIN: 3604-6491; e-mail: karamova@cnikvi.ru

Liaisan K. Davletbaeva — ORCID iD: https://orcid.org/0000-0003-4952-0800; e-mail: lesya-g|@mail.ru

Статья поступила в редакцию: 01.09.2021

Принята к публикации: 05.10.2021

Дата публикации: 15.10.2021
Submitted: 01.09.2021

Accepted: 05.10.2021

Published: 15.10 .2021 